\title{
Research Article \\ Effect of Phosphoric Acid Concentration on the Optical Properties of Partially Phosphorylated PVA Complexes
}

\author{
Asmalina Mohamed Saat ${ }^{1,2}$ and Mohd Rafie Johan ${ }^{2}$ \\ ${ }^{1}$ Malaysian Institute of Marine Engineering Technology, Universiti Kuala Lumpur, 32200 Lumut, Perak, Malaysia \\ ${ }^{2}$ Nanomaterials Engineering Research Group, Advanced Materials Research Laboratory, Department of Mechanical Engineering, \\ Faculty of Engineering, Universiti Malaya, 50603 Kuala Lumpur, Malaysia
}

Correspondence should be addressed to Asmalina Mohamed Saat; asmalina@unikl.edu.my

Received 10 July 2014; Revised 23 October 2014; Accepted 25 October 2014; Published 18 November 2014

Academic Editor: Yulin Deng

Copyright (C) 2014 A. Mohamed Saat and M. R. Johan. This is an open access article distributed under the Creative Commons Attribution License, which permits unrestricted use, distribution, and reproduction in any medium, provided the original work is properly cited.

Partially phosphorylated polyvinyl alcohol (PPVA) films were prepared at five mole ratios of phosphoric acid (PA) using solution casting technique. The optical properties of the PPVA films were examined using UV-visible (UV) and photoluminescence (PL) spectroscopy. The UV absorption spectra reveal that the absorption peaks are blue-shifted with an increase in PA concentration added to the pure PVA. The PL spectra show the presence of peaks which are characteristic of isotactic (389-398, 460-462 nm), syndiotactic $(418-420 \mathrm{~nm})$, and atactic $(440-446 \mathrm{~nm})$ configurations of the PPVA. The results also show the peak of O-P-O bonding at a wavelength range of $481-489 \mathrm{~nm}$.

\section{Introduction}

Polyvinyl alcohols (PVA) have garnered much interest over the years due to their vast range of applications. PVA is a material where its physicochemical properties are dependent on the degree of polymerization, hydrolysis, and distribution of its hydroxyl groups $(\mathrm{OH})$. Partially phosphorylated PVA (PPVA) is produced by reacting PVA with a very strong phosphoric acid (PA) [1]. The use of PPVA is commonplace in the industry due to its array of favorable properties such as excellent film forming [2], conductivity [3], ion exchange [4], chemical resistance [5], and flammability [6]. Variations of the PA concentration will result in a color change in the complexes from transparent to brown [7]. However, it is found that only a few studies have studied the reaction between PVA and PA, with emphasis on the optical properties of the product [8]. The UV-visible spectra of a $\mathrm{PVA} / \mathrm{H}_{3} \mathrm{PO}_{4} / \mathrm{CV}$ system in [9] show that the absorption peaks can be mainly ascribed to $\mathrm{CV}$ and the complexes of $\mathrm{PVA} / \mathrm{H}_{3} \mathrm{PO}_{4}$ are said to have very weak absorption peaks. Two intense characteristic absorption peaks of phosphotungstic acid are observed at 199.3 and $270.1 \mathrm{~nm}$ for PWA/PVA composite membranes, which proves the interactions among PWA, PVA, and phosphate groups [10]. The UV-visible spectra of a Cu II-PPVA system recorded at $20-300 \mathrm{~nm}$ and $550-800 \mathrm{~nm}$ show the presence of two absorption bands at 253 and $780 \mathrm{~nm}$ for a $\mathrm{pH}$ of 2.5-3. The system becomes blue-shifted when the pH level is increased to 7, in which the absorption peak shifts to a lower wavelength at $218 \mathrm{~nm}$ [4]. In [8], annealing of PPVA at $70^{\circ} \mathrm{C}$ for $20 \mathrm{~h}$ produces an absorption peak at $350 \mathrm{~nm}$. The peak intensity increases and becomes more visible with an increase in $\mathrm{PA}$ concentration. The absorption band of $\mathrm{PVA} / \mathrm{H}_{3} \mathrm{PO}_{4}$ and methylene blue is observed at $425,605,675$, and $750 \mathrm{~nm}$. The appearance of peak at $605-750 \mathrm{~nm}$ is due to methylene blue whereas the peak at $425 \mathrm{~nm}$ is due to the presence of $\mathrm{PVA} / \mathrm{H}_{3} \mathrm{PO}_{4}[7]$.

The photoluminescence (PL) spectra for PPVA films exhibit broad emission bands which correspond to $n \leftarrow \pi^{*}$ electronic transition of the $\mathrm{OH}$ groups characteristic of three distinctive polymer configurations (isotactic, syndiotactic, and atactic) in the aqueous solution. Such broad emissions may also be due to oxygen vacancies and the presence of impurities [11]. Basically, tacticity is used to describe the way pendent groups on a polymer chain are arranged on 
a polymer backbone. In isotactic PVA, the extended-chain backbone and the entire $\mathrm{OH}$ groups lie on the same side of the plane, whereas in syndiotactic PVA, the $\mathrm{OH}$ group alternates from one side of the plane to another. The sequential distribution of $\mathrm{OH}$ groups on either side of the backbone can be explored to design a regular interchain in bridging a layered structure. Finally, there is no particular distribution for $\mathrm{OH}$ groups in atactic PVA [12]. The PL spectra for pure PVA dispersed in small polymer molecules in water $(\sim 4.0 \mathrm{~g} / \mathrm{dL})$ exhibit three distinct bands at 415,437 , and $465 \mathrm{~nm}$ after excitation at 400 and $350 \mathrm{~nm}$ [12]. Deconvolution of the PL spectra for a PVA/ZnO system shows that the peaks at $400,415,439$, and $465 \mathrm{~nm}$ are attributed to pure PVA whereas the peak at $506 \mathrm{~nm}$ is due to the presence of $\mathrm{ZnO}$ nanoparticles [11]. However, it is observed from existing literature that PL spectroscopy has not been carried out for analysis of PPVA complexes and thus the goal of this study is to examine the optical properties of PPVA complexes at different concentrations of PA using UV-visible and PL spectroscopy.

\section{Materials and Methodology}

Partially hydrolyzed polyvinyl alcohol (PVA, 86.7\%) and phosphoric acid/orthophosphoric acid (PA, 85\%) were sourced from R\&M Chemicals. PVA was mixed with PA at five mole ratios $(0.1,0.2,0.3,0.4$, and 0.5) and stirred at $90^{\circ} \mathrm{C}$ for $2 \mathrm{~h}$ to form partially phosphorylated PVA (PPVA). The solutions were poured into separate Petri dishes and dried at room temperature for 3 days. The absorption spectra of the PPVA films were recorded using Cary $50 \mathrm{UV}$-visible spectrophotometer whereas the PL spectra of the PPVA samples were recorded using Perkin Elmer LS 55 luminescence spectroscopy within a range of 200-900 $\mathrm{nm}$ at five excitation peaks $(272,300,350,400$, and $500 \mathrm{~nm})$.

\section{Results and Discussion}

3.1. UV-Visible Spectroscopy Analysis. The absorption spectra for pure PVA and PPVA films at five mole ratios are shown in Figure 1. The pure PVA exhibits absorption bands at 204, 277, and $324 \mathrm{~nm}$ while the reaction between PVA and PA shows only one absorption band at $274 \mathrm{~nm}$ due to the interaction of PVA with the phosphate component [10]. The position of the absorption bands shifts towards lower wavelengths and are found to be within the range of $274-270 \mathrm{~nm}$ with an increase in mole ratio. An et al. [4] observed the occurrence of absorption peaks for metal Cu (II)-PPVA solution complexes with $\mathrm{pH} 2.5-3.0$ at 253 and $780 \mathrm{~nm}$ and the absorption peaks shift to a lower wavelength $(218 \mathrm{~nm})$ when the $\mathrm{pH}$ level was increased to 7 . The results obtained in this study agree well with the findings of An et al. [4]. The blue shifts indicate the formation of inter/intramolecular hydrogen bonding, primarily bonding between the PA ions and adjacent $\mathrm{OH}$ groups. The bonds reflect variations of the energy band gap resulting from the variations of crystallinity within the polymer matrix [13]. It is also observed that the intensity of the absorption bands increases with an increase in mole ratio.

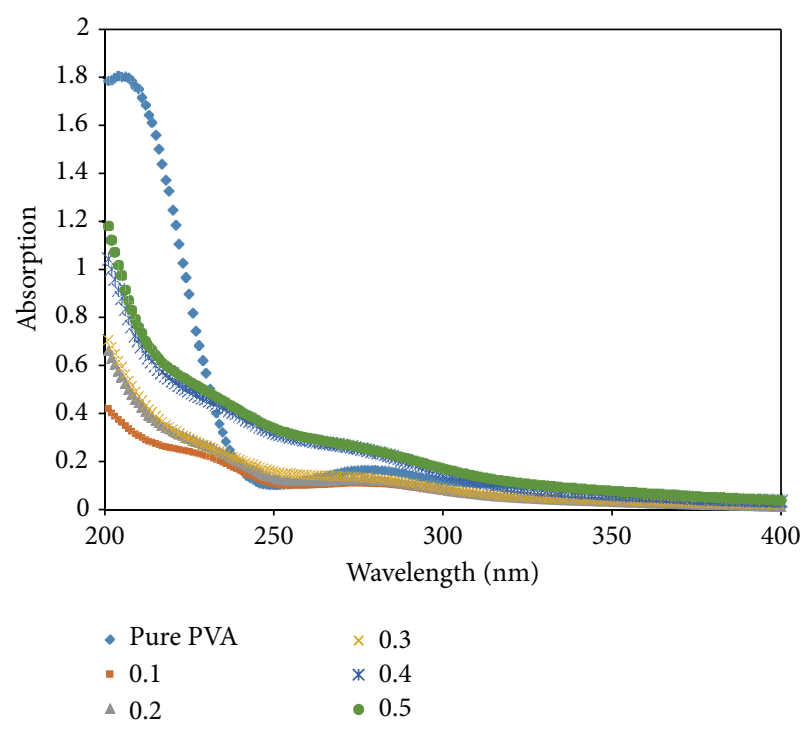

FIgURE 1: Absorption spectra for pure PVA and PPVA films at five PA: PVA mole ratios.

A high absorption intensity indicates that more absorption states or defect energy bands exist within the complexes. The absorption peak becomes less visible at the highest mole ratio (0.5) and it is observed that the polymer film becomes oily and wet, which is attributed to the plasticization effect associated with an increase in PA concentration [7]. The results are in good agreement with the findings of Mitra et al. [14] who observed the absence of absorption peaks at high PA content for a mixture of PVA, PEG, PA, and gold nanoparticles.

The optical band gap is defined as the difference between the bottom of the conduction band and the top of the valence band, and it basically represents optical transition. The absorption coefficient $\alpha$ needs to be determined first in order to determine the optical band gap of the films and is given by the following formula:

$$
\alpha(\nu)=2.303 \frac{A}{d}
$$

where $A$ is the absorbance and $d$ is the film thickness. Davis and Mott [15] reported that electronic transition occurs near the absorption edge and can be determined by plotting $(\alpha h \nu)^{2}$ as a function of photon energy $(h \nu)$. The absorption coefficient $\alpha$ is rewritten as

$$
\alpha(\nu)=\beta \frac{\left(h \nu-E_{g}\right)^{2}}{h \nu},
$$

where $\beta$ is a constant, $h \nu$ is the photon energy, and $E_{g}$ is the optical band gap. In this study, the values of $(\alpha h \nu)^{2}$ are plotted as a function of photon energy $(h \nu)$ as shown in Figure 2, and the $E_{g}$ values are extracted to determine the direct transitions by extrapolating $(\alpha h v)^{2}=0$. The optical band gap values determined from the plot are presented in Table 1 


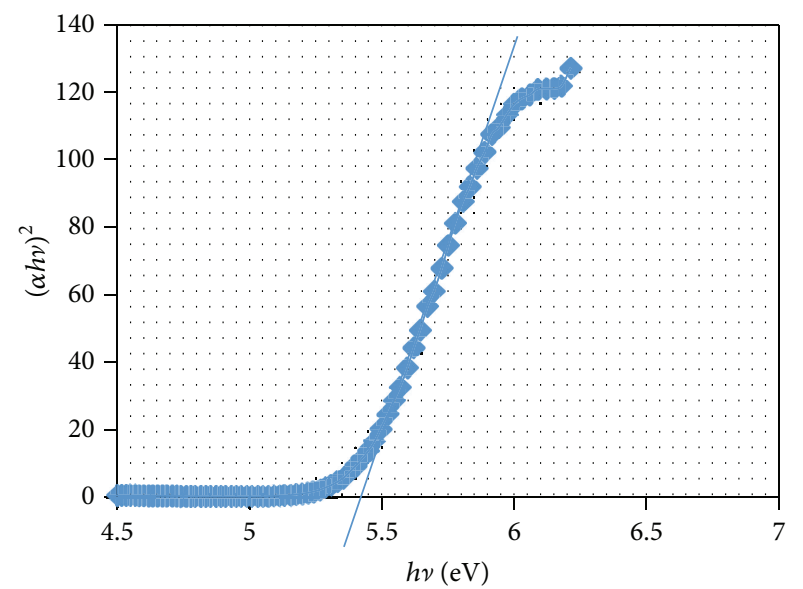

(a)

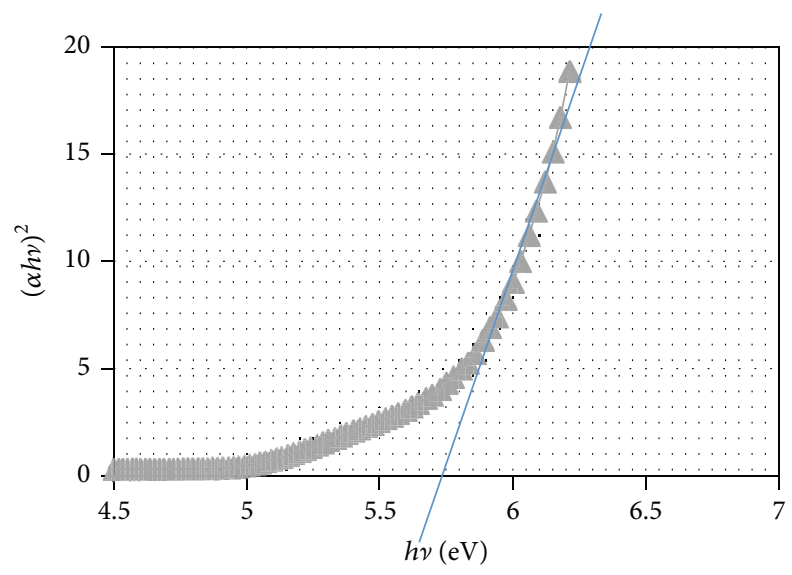

(c)

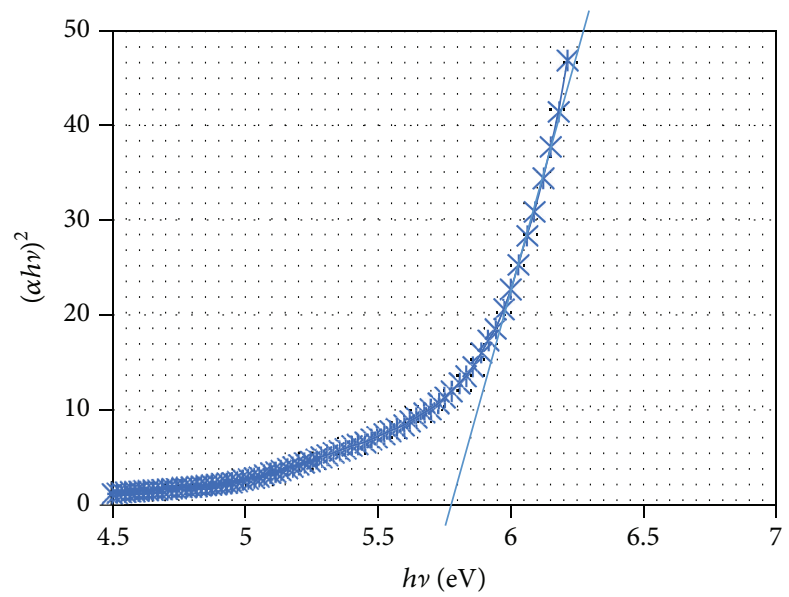

(e)

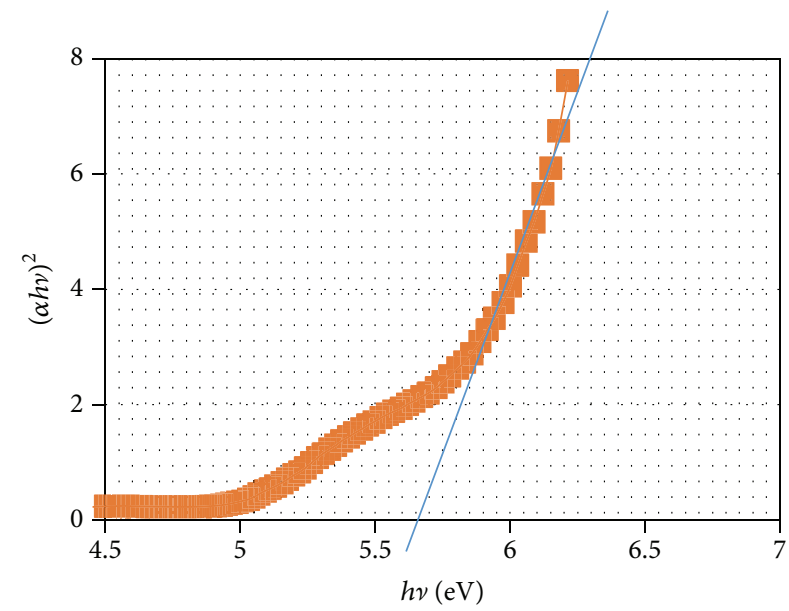

(b)

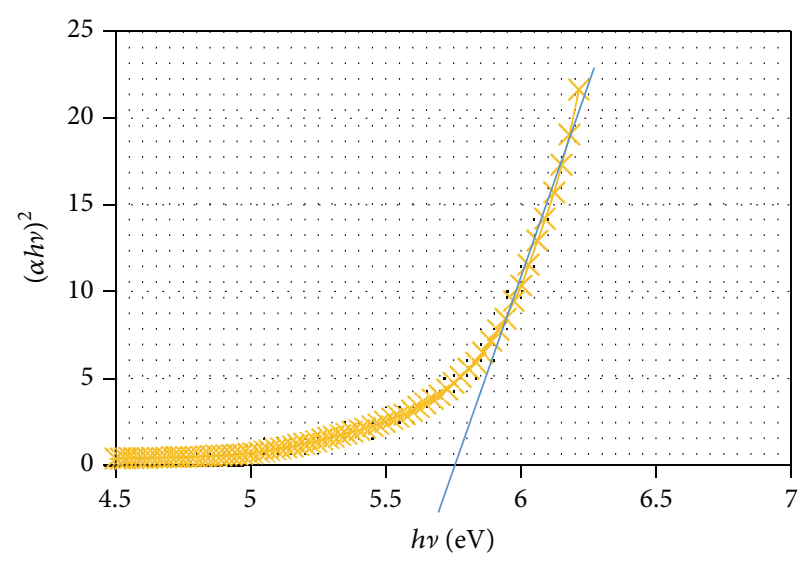

(d)

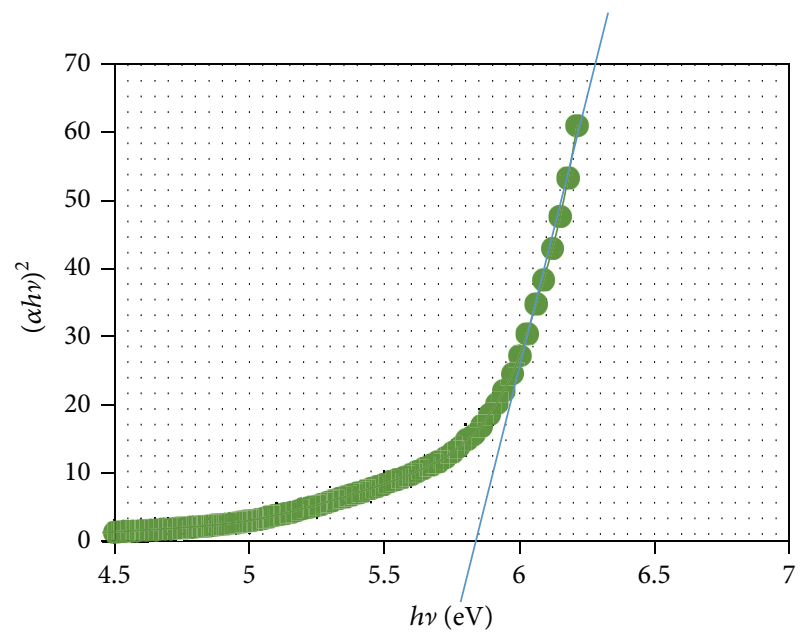

(f)

FIGURE 2: Plot of $(\alpha h v)^{2}$ versus photon energy (hv) for pure PVA and PPVA films with five mole ratios: (a) pure PVA; (b) 0.1; (c) 0.2; (d) 0.3; (e) 0.4 ; and (f) 0.5 . 
TABLE 1: Optical parameters for pure PVA and PPVA films.

\begin{tabular}{lcc}
\hline Sample (mole ratio) & $\begin{array}{c}\text { Optical band gap, } \\
E_{g}(\mathrm{eV})\end{array}$ & $\begin{array}{c}\text { Absorption peak } \\
(\mathrm{nm})\end{array}$ \\
\hline Pure PVA & 5.45 & 277 \\
0.1 & 5.67 & 275 \\
0.2 & 5.75 & 273 \\
0.3 & 5.77 & 272 \\
0.4 & 5.79 & 271 \\
0.5 & 5.83 & 270 \\
\hline
\end{tabular}

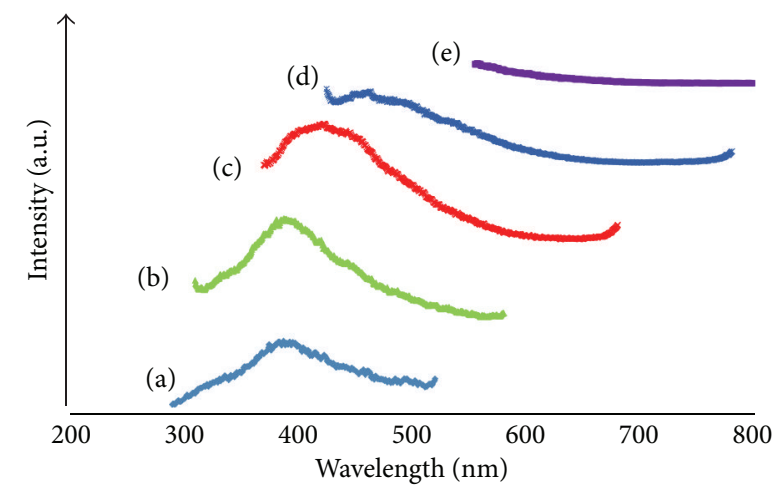

FIGURE 3: PL spectra of pure PVA and PPVA samples prepared with a mole ratio of 0.3 at five excitation wavelengths: (a) 272; (b) 300; (c) 350; (d) 400; and (e) $500 \mathrm{~nm}$.

and it can be seen that the $E_{g}$ increases with increasing mole ratio, which indicates that the concentration of PA plays a significant role in reducing defects in the films. These defects produce localized states in the optical band gap, in which the localized states overlap one another. Fewer overlaps are indicative of increasing energy band gap due to the increase in PA concentration within the polymer matrix. In other words, an increase in the optical band gap reflects a decrease in the degree of disorder in the polymer films due to changes in the polymer structure.

3.2. Photoluminescence (PL) Spectrophotometry Analysis. The PL spectra for pure PVA and PPVA samples prepared with a mole ratio of 0.3 at five excitation wavelengths $(272,300$, 350, 400, and $500 \mathrm{~nm}$ ) are shown in Figure 3. It can be observed that the peak emissions are red-shifted with an increase in excitation wavelength. The broad band emissions appear around the green-yellow region with the exception of $500 \mathrm{~nm}$ as it is observed that there are no emission peaks. The broad band emissions correspond to the $n \leftarrow \pi^{*}$ electronic transition of the $\mathrm{OH}$ groups which are characteristic of three distinct polymer configurations in the aqueous solution, that is, isotactic(i), syndiotactic(s), and atactic(a).

The PL spectra for pure PVA and PPVA samples with five mole ratios at an excitation wavelength of $300 \mathrm{~nm}$ are shown in Figure 4. It can be seen that the emission bands shift towards lower wavelengths within a range of $412-389 \mathrm{~nm}$ with an increase in mole ratio. Furthermore, the intensity of

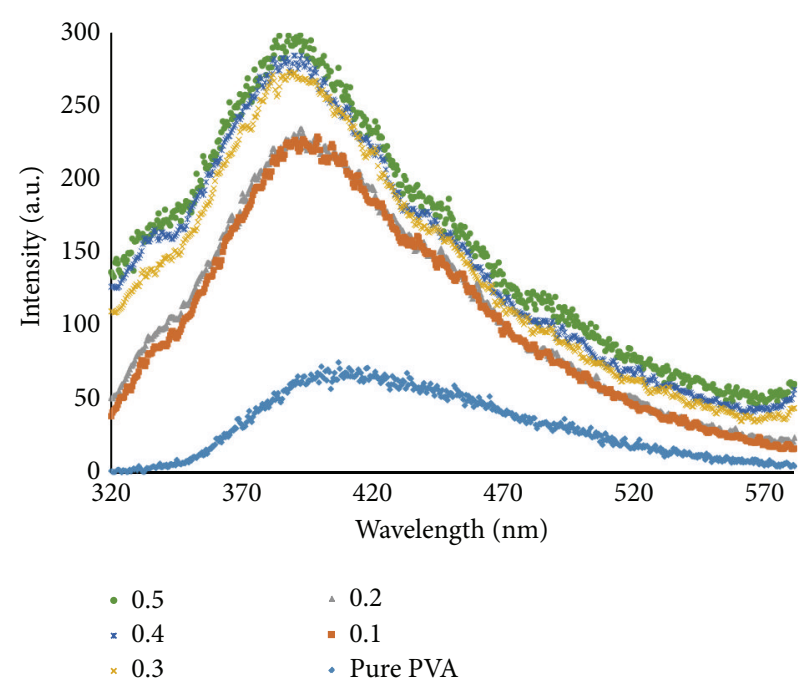

Figure 4: PL spectra of pure PVA and PPVA films with five mole ratios $(0.1,0.2,0.3,0.4$, and 0.5$)$ at an excitation wavelength of $300 \mathrm{~nm}$.

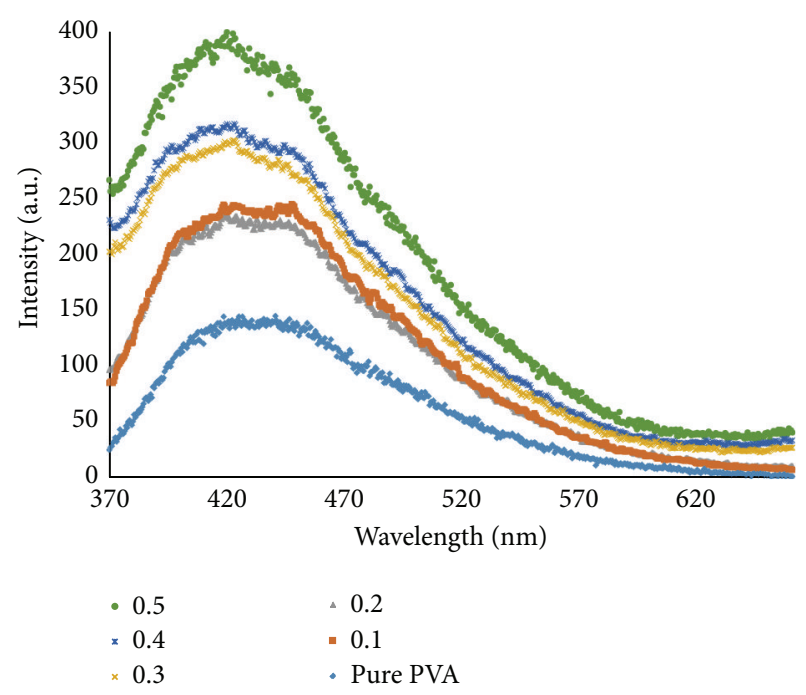

Figure 5: PL spectra of pure PVA and PPVA films with five mole ratios $(0.1,0.2,0.3,0.4$, and 0.5$)$ at an excitation wavelength of $350 \mathrm{~nm}$.

the emission bands increases with an increase in mole ratio, which proves that the phosphate element interacts with the PVA in the complexed PPVA.

A strong PL resonance excitation $\left(\lambda_{\text {ext }}=300 \mathrm{~nm}\right)$ appears within a wavelength range of $389-398 \mathrm{~nm}$ due to $\mathrm{OH}$ stretching vibration $v_{1}$ (or overtone) of the i-PVA/PPVA configuration.

The PL spectra for pure PVA and PPVA samples with five mole ratios at an excitation wavelength of 350 and $400 \mathrm{~nm}$ are shown in Figures 5 and 6 , respectively. The $350 \mathrm{~nm}$ excitation wavelength resonates the excited electronic states at a broad range of $418-421 \mathrm{~nm}$ and $441-446 \mathrm{~nm}$ in the s- and 
TABle 2: Photoluminescence data for pure PVA and PPVA with five mole ratios $(0.1,0.2,0.3,0.4$, and 0.5$)$ at three excitation wavelengths $(300,350$, and $400 \mathrm{~nm})$.

\begin{tabular}{|c|c|c|c|c|c|c|}
\hline \multirow{2}{*}{ Excitation wavelength $\lambda_{\text {exc }}(\mathrm{nm})$} & \multirow{2}{*}{$\frac{\text { Samples (mole ratio) }}{\text { Pure PVA }}$} & \multicolumn{2}{|c|}{ Band position (nm) } & \multirow{2}{*}{$\frac{\text { Intensity }}{70}$} & \multicolumn{2}{|c|}{ Assignment } \\
\hline & & 412 & & & s-PVA & \\
\hline & 0.1 & 398 & & 225 & i-PPVA & \\
\hline \multirow[t]{6}{*}{300} & 0.2 & 396 & & 230 & i-PPVA & \\
\hline & 0.3 & 391 & & 270 & i-PPVA & \\
\hline & 0.4 & 389 & & 285 & i-PPVA & \\
\hline & 0.5 & 389 & & 295 & i-PPVA & \\
\hline & Pure PVA & 418 & 440 & 148,148 & s-PVA & a-PVA \\
\hline & 0.1 & 418 & 441 & 245,248 & s-PPVA & a-PPVA \\
\hline \multirow[t]{6}{*}{350} & 0.2 & 421 & 444 & 235,225 & s-PPVA & a-PPVA \\
\hline & 0.3 & 429 & 442 & 305,280 & s-PPVA & a-PPVA \\
\hline & 0.4 & 421 & 443 & 315,300 & s-PPVA & a-PPVA \\
\hline & 0.5 & 420 & 446 & 400,360 & s-PPVA & a-PPVA \\
\hline & Pure PVA & 462 & 500 & 135,150 & i-PVA & \\
\hline & 0.1 & 462 & 489 & 125,115 & i-PPVA & \\
\hline \multirow[t]{4}{*}{400} & 0.2 & 460 & 485 & 125,115 & i-PPVA & \\
\hline & 0.3 & 468 & 481 & 180,160 & i-PPVA & \\
\hline & 0.4 & 462 & 482 & 199,175 & i-PPVA & \\
\hline & 0.5 & 461 & 481 & 265,235 & i-PPVA & \\
\hline
\end{tabular}

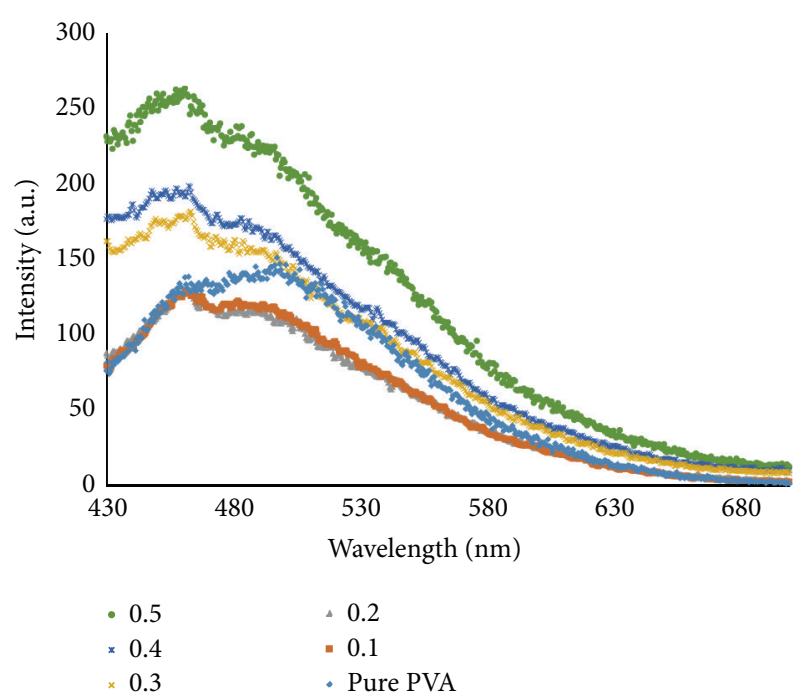

FIgURE 6: PL spectra of pure PVA and PPVA films with five mole ratios $(0.1,0.2,0.3,0.4$, and 0.5$)$ at an excitation wavelength of $400 \mathrm{~nm}$.

a-PVA/PPVA configuration, respectively, as shown in Table 2. In general, the emission peak shifts towards to longer wavelengths with an increase in excitation wavelength. In other words, the samples are red-shifted, whereby the emission peak for pure PVA shifts from 418 to $440 \mathrm{~nm}$, whereas the emission peak for PPVA with the highest mole ratio shifts from 420 to $446 \mathrm{~nm}$ due to the $\mathrm{O}-\mathrm{X}-\mathrm{O}$ phosphors. Refrence [16] stated that the $\mathrm{O}-\mathrm{X}-\mathrm{O}$ phosphors produce defects in the luminescent emissions which are intrinsically related to oxygen vacancies in the complexes at $440 \mathrm{~nm}$. Consequently, the emission peaks appear in multiple overlapping peaks with an increase in intensity. This may be due to the numerous absorption states of various defects existing in the PPVA. A similar trend was also observed by [7], but with the existence of $\mathrm{PVA} / \mathrm{H}_{3} \mathrm{PO}_{4}$ peak at a wavenumber of $425 \mathrm{~nm}$. Broad emission bands occur within a range of 462-468 $\mathrm{nm}$ and 481$489 \mathrm{~nm}$ when the excitation is increased to $\lambda_{\text {ext }}=400 \mathrm{~nm}$, as shown in Figure 6.

It can be deduced from the results that the PPVA complexes mainly consist of isotactic, atactic, and syndiotactic PVA/PPVA configurations. The s-PVA/PPVA gives a stable structure, which complicates the dissolving process in pure water. The free $\mathrm{OH}$ groups react with $\mathrm{PA}$ in a more stable equilibrium structure and only a few $\mathrm{OH}$ groups are free to produce PPVA.

The molecular structures of isotactic, syndiotactic, and atactic configurations of PPVA are illustrated in Figure 7. The photoluminescence data for pure PVA and PPVA prepared with five mole ratios at three excitation wavelengths are summarized in Table 2.

The energy level diagram which shows PL emissions and nonradiative processes at 300,350 , and $400 \mathrm{~nm}$ is shown in Figures 8, 9, and 10, respectively. All of the energy level diagram was drawn by referring to PVA energy level diagram as presented by [12]. The $300 \mathrm{~nm}$ excitation resonates 


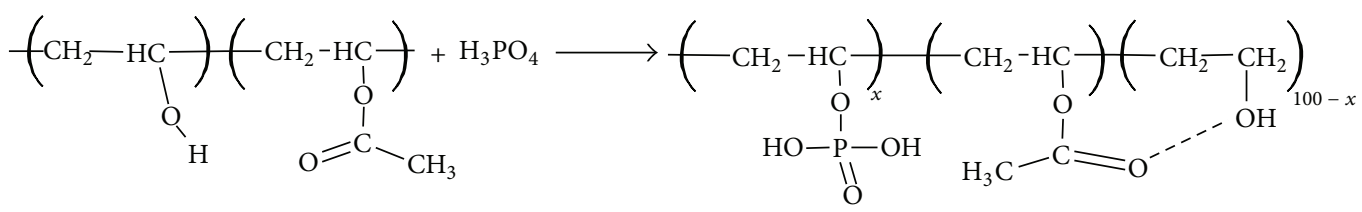

(a) Monomer PPVA<smiles>CCC(O)CC(CC(O)CC(CC(O)CC(CC)OP(=O)(O)O)OP(=O)(O)O)OP(=O)(O)O</smiles>

(b) Isotactic PPVA (i-PPVA)<smiles>C=CC(O)CC(CC(O)CC(CC(O)CC(CC(O)CC(CCC)OP(=O)(O)O)OP(=O)(O)O)OP(=O)(O)O)OP(=O)(O)O</smiles>

(c) Syndiotactic PPVA (s-PPVA)<smiles>CCC(O)CC(CC(O)CC(CC(O)CC(CC(O)CC(CC(C)(C)C)OP(=O)(O)O)OP(=O)(O)O)OP(=O)(O)O)OP(=O)(O)O</smiles>

(d) Atactic PPVA (a-PPVA)

FIgURE 7: Schematic diagram of PPVA molecular structures: (a) monomer PPVA; (b) isotactic PPVA; (c) syndiotactic PPVA; and (d) atactic PPVA.

the excited electronic states in s-PVA at $412 \mathrm{~nm}$ (Table 2). The remaining band falls within $389-398 \mathrm{n}$ and is the most intense band of the PL spectra and is ascribed to i-PPVA, as shown in Figure 8.

\section{Conclusion}

The effect of phosphoric acid concentration on the optical properties of PPVA complexes has been investigated in this study. The UV-visible spectra reveal notable variations in peak intensity and position with an increase in mole ratio due to the interactions between $\mathrm{PA}$ ions and $\mathrm{OH}$ groups. The optical band gap of the PVA slightly increases with the addition of PA due to the decrease in the formation of defects within the polymer matrix.

It is observed that there are five distinct bands in the PL spectra at 391, 429, 442, 468, and $481 \mathrm{~nm}$ after excitation at five wavelengths $(272,300,350,400$, and $500 \mathrm{~nm})$ for PPVA films with a mole ratio of 0.3 . The peak intensity varies nonlinearly with PA concentration, depending on the wavelength excitation. The five PL bands are attributed to 


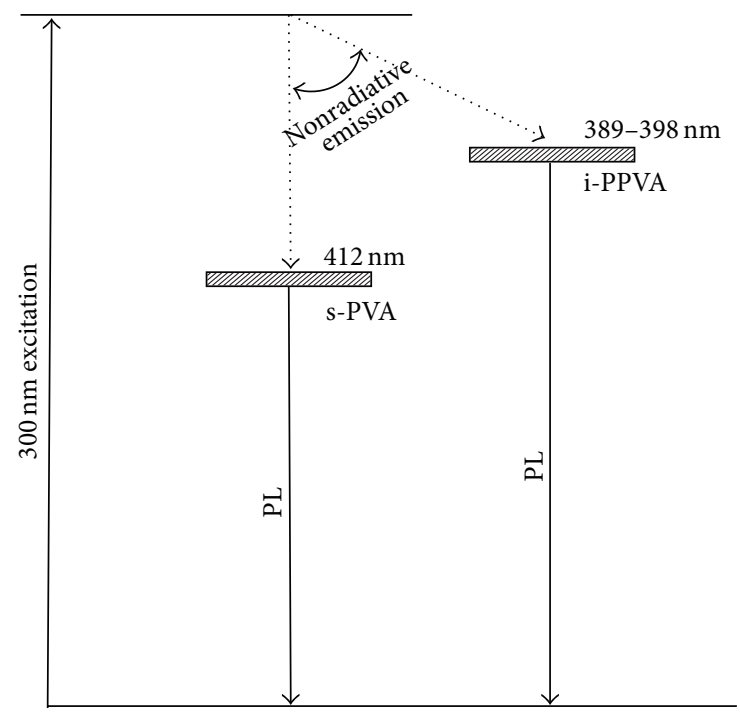

FIgURE 8: Energy level diagram which shows PL emissions and nonradiative processes occurring simultaneously in s-PVA and iPPVA polymer molecules at a resonance excitation of $300 \mathrm{~nm}$.

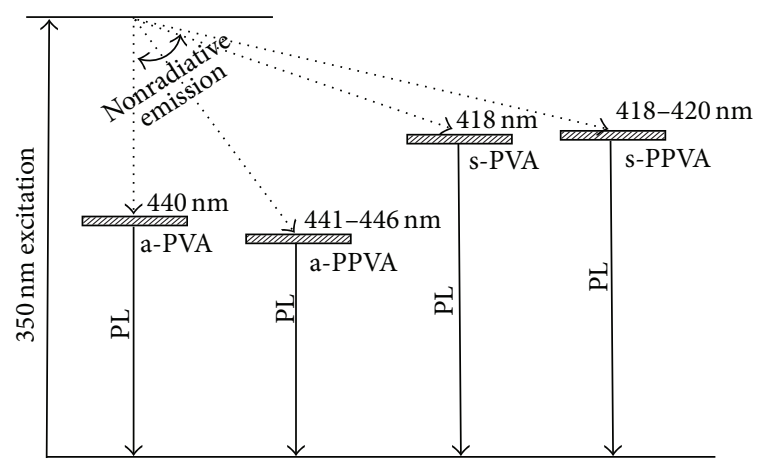

FIgURE 9: Energy level diagram which shows PL emissions and nonradiative processes occurring simultaneously in a-PVA and sPPVA polymer molecules at resonance excitation of $350 \mathrm{~nm}$.

the $n \leftarrow \pi^{*}$ transition of the free $\mathrm{OH}$ groups in s-, a-, and i-PPVA configurations. The interactions between $\mathrm{H}_{2} \mathrm{O}$ and PA modify bridging in the s-PPVA, which changes to aPPVA configuration at higher PA concentrations. The lack of highly sensitive bridging makes the i-PPVA more sensitive to $\mathrm{H}$-bonding with $\mathrm{H}_{2} \mathrm{O}$ molecules. In general, the findings of this study are beneficial as they enhance understanding on the modified structures and optical properties of PPVA polymer films, which will assist researchers in developing PPVA polymers for new applications.

\section{Conflict of Interests}

The authors declare that there is no conflict of interests regarding the publication of this paper.

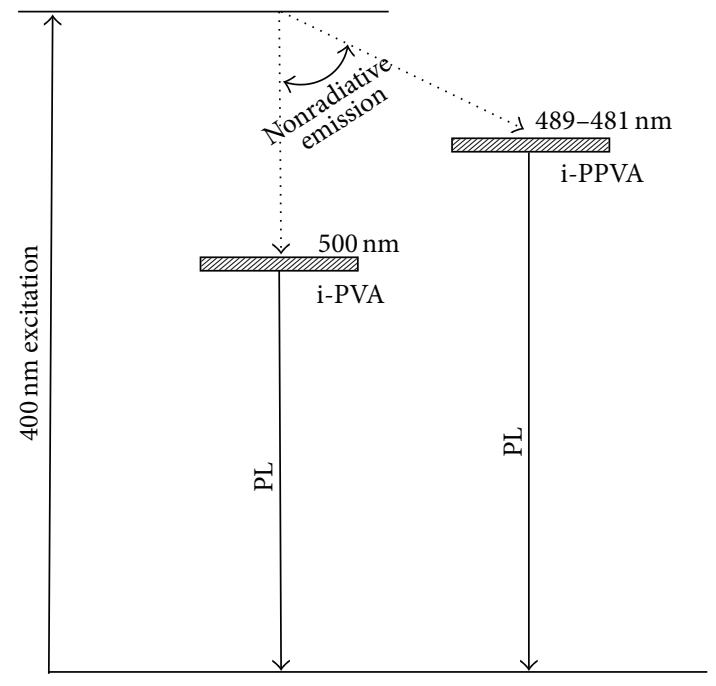

FIgURE 10: Energy level diagram which shows PL emissions and nonradiative processes occurring simultaneously in i-PVA and iPPVA polymer molecules at a resonance excitation of $400 \mathrm{~nm}$.

\section{Acknowledgments}

The authors greatly acknowledge the financial support provided by University of Malaya under the UM PPP Grant (Grant nos. PS115-2010B and PV129/2012A) as well as UMRG (RP011C-13AET). Asmalina Mohamed Saat is indebted to Universiti Kuala Lumpur for their financial support and for granting study leave.

\section{References}

[1] J. G. Pritchard, Poly(vinyl alcohol): Basic Properties and Uses, Macdonald \& Co., London, UK, 1970.

[2] F. Chen and P. Liu, "High electrically conductive polyaniline/partially phosphorylated poly(vinyl alcohol) composite films via aqueous dispersions," Macromolecular Research, vol. 19, no. 9, pp. 883-890, 2011.

[3] L. Yuan, X.-H. Lu, X. Xiao et al., "Flexible solid-state supercapacitors based on carbon nanoparticles $/ \mathrm{MnO}_{2}$ nanorods hybrid structure," ACS Nano, vol. 6, no. 1, pp. 656-661, 2012.

[4] Y. An, T. Ushida, M. Suzuki, T. Koyama, K. Hanabusa, and H. Shirai, "Complex formation of partially phosphorylated poly(vinyl alcohol), with metal ions in aqueous solution," Polymer, vol. 37, no. 14, pp. 3097-3100, 1996.

[5] F. Chen and P. Liu, "Conducting polyaniline nanoparticles and their dispersion for waterborne corrosion protection coatings," ACS Applied Materials \& Interfaces, vol. 3, no. 7, pp. 2694-2702, 2011.

[6] P. Joseph and S. Tretsiakova-Mcnally, "Reactive modifications of some chain- and step-growth polymers with phosphoruscontaining compounds: Effects on flame retardance-a review," Polymers for Advanced Technologies, vol. 22, no. 4, pp. 395-406, 2011.

[7] P. R. Somani, R. Marimuthu, K. Viswanath, and S. Radhakrishnan, "Thermal degradation properties of solid polymer electrolyte (poly(vinyl alcohol)+phosphoric acid)/methylene blue composites," Polymer Degradation and Stability, vol. 79, pp. 7783, 2003. 
[8] A. Iribarren, A. L. Marzo, and H. Lemmetyinen, "Absorption in polyvinyl alcohol phosphoric acids films under different processing conditions. Kinetic study," Revista Cubana De Quimica, vol. 21, no. 2, pp. 3-9, 2009.

[9] P. R. Somani, A. K. Viswanath, R. C. Aiyer, and S. Radhakrishnan, "Novel dye + solid polymer electrolyte material for optical humidity sensing," Organic Electronics, vol. 2, no. 2, pp. 83-88, 2001.

[10] L. Li, L. Xu, and Y. Wang, "Novel proton conducting composite membranes for direct methanol fuel cell," Materials Letters, vol. 57, no. 8, pp. 1406-1410, 2003.

[11] D. M. Fernandes, A. A. W. Hechenleitner, S. M. Lima, L. H. C. Andrade, A. R. L. Caires, and E. A. G. Pineda, "Preparation, characterization, and photoluminescence study of PVA/ZnO nanocomposite films," Materials Chemistry and Physics, vol. 128, no. 3, pp. 371-376, 2011.

[12] S. Ram and T. K. Mandal, "Photoluminescence in small isotactic, atactic and syndiotactic PVA polymer molecules in water," Chemical Physics, vol. 303, no. 1-2, pp. 121-128, 2004.

[13] N. R. Rao, Ultraviolet and Visible Spectroscopy: Chemical Applications, Butterworth, London, UK, 1967.

[14] S. Mitra, S. Chandra, P. Patra, P. Pramanik, and A. Goswami, "Novel fluorescent matrix embedded carbon quantum dots for the production of stable gold and silver hydrosols," Journal of Materials Chemistry, vol. 21, no. 44, pp. 17638-17641, 2011.

[15] E. A. Davis and N. F. Mott, "Conduction in non-crystalline systems V. Conductivity, optical absorption and photoconductivity in amorphous semiconductors," Philosophical Magazine, vol. 22, pp. 903-922, 1970.

[16] H. R. Chen, J. L. Shi, Y. Yang, Y. S. Li, D. S. Yan, and C. S. Shi, "Violet-blue photoluminescent properties of mesoporous zirconia modified with phosphoric acid," Applied Physics Letters, vol. 81, no. 15, pp. 2761-2763, 2002. 

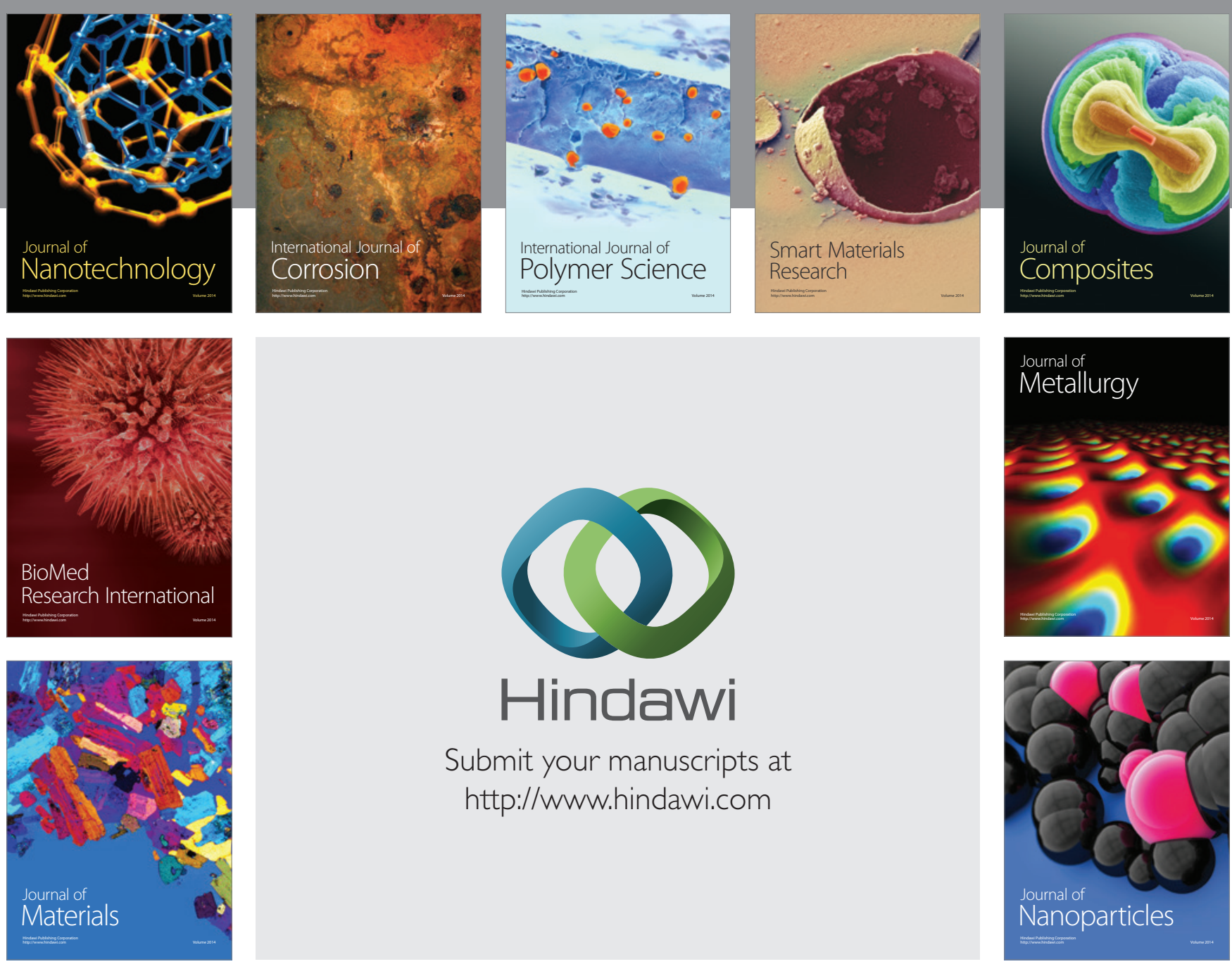

Submit your manuscripts at http://www.hindawi.com
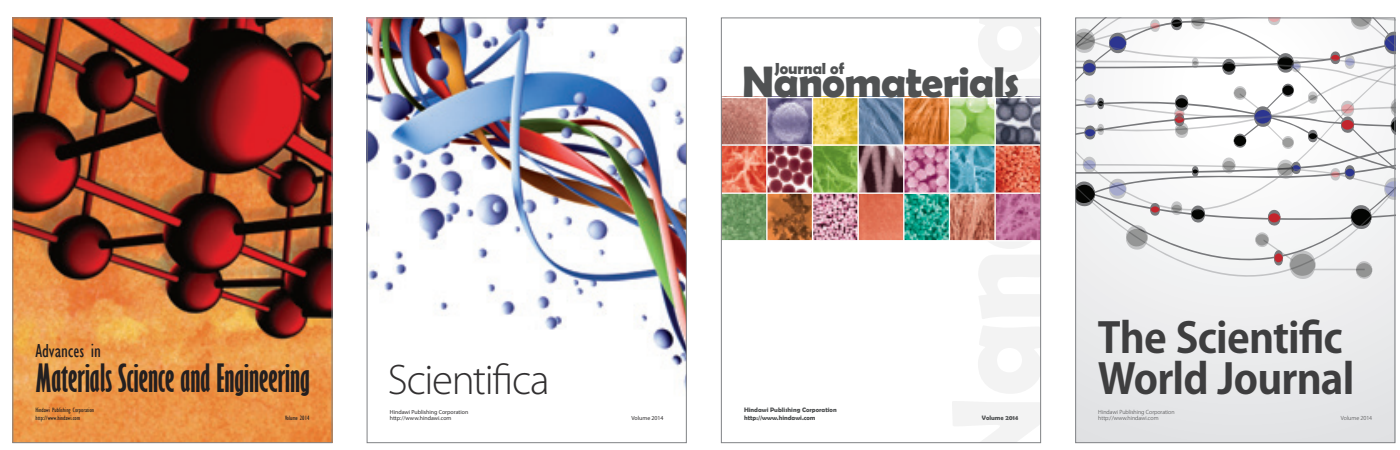

\section{The Scientific World Journal}
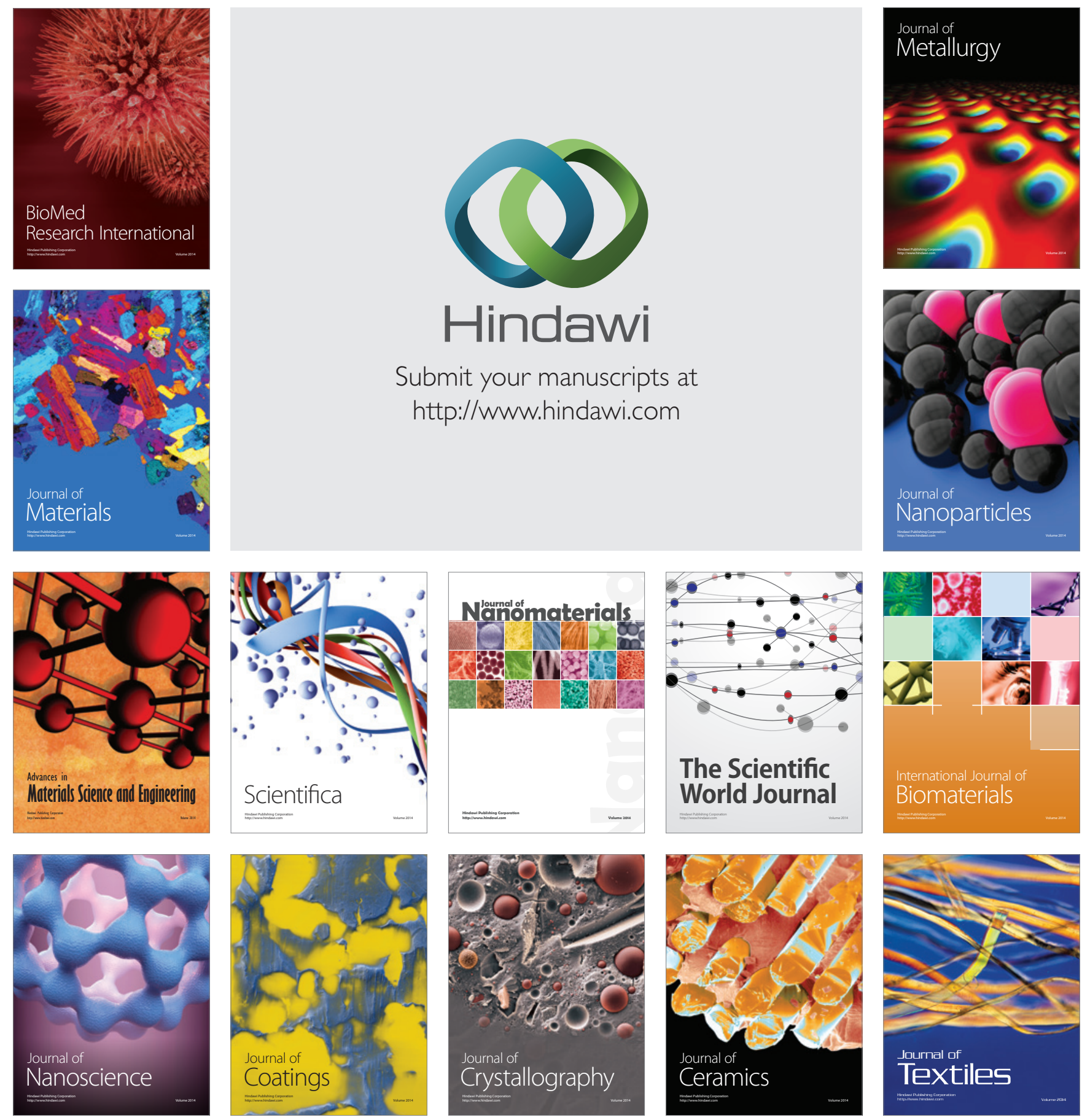